\title{
Contemporary analysis of charges and mortality in the use of extracorporeal membrane oxygenation: $\mathrm{A}$ cautionary tale
}

J. W. Awori Hayanga, MD, MPH, ${ }^{a}$ Jonathan Aboagye, MD, MPH, ${ }^{b}$ Errol Bush, MD, ${ }^{b}$ Joseph Canner, PhD, ${ }^{b}$ Heather K. Hayanga, MD, MPH, ${ }^{\mathrm{c}}$ Alyssa Klingbeil, MSN, CRNP, ${ }^{\mathrm{d}, \mathrm{e}}$ Paul McCarthy, MD, ${ }^{\mathrm{a}, \mathrm{f}}$ James Fugett, MS, ${ }^{a}$ Ghulam Abbas, MD, MHS, ${ }^{a}$ and Vinay Badhwar, MD ${ }^{\mathrm{a}}$

\section{ABSTRACT}

Objective: The use of extracorporeal membrane oxygenation (ECMO) has increased exponentially. Costs and outcomes, however, vary considerably by indication. We sought to elucidate and quantify these differences.

Methods: Adult patients supported on ECMO between 2008 and 2016 were analyzed using the Nationwide Inpatient Sample. We divided the study period into an early (2008-2013) and late period (2013-2016). The primary outcome was hospital charges, and the secondary outcomes were mortality, length of stay (LOS), and duration of ECMO support. These were stratified by the 5 most common indications: postcardiotomy shock (PCS), cardiogenic shock (CS), severe acute respiratory failure (SARF), heart (HT), and lung transplantation (LT). Both patient and hospital characteristics were assessed. Charges were adjusted for inflation and analyzed using a generalized linear model with gamma distribution. Pairwise comparison with Bonferroni correction was used to evaluate the cost and multivariate logistic regression to assess the risk of mortality.

Results: Data pertaining to 15,829 adult patients were evaluated. Mean age of the entire cohort was 52.8 years, $8895(56 \%)$ were white, and 10,278 (65\%) were male. PCS was the predominant indication for ECMO (39\%), followed by CS $(37 \%)$. SARF accounted for $15 \%$ and HT and LT accounted for $3.9 \%$ and $5.4 \%$, respectively. Mean LOS and duration of ECMO support were 23.4 days and 5.3 days respectively. Mean hospital charges per hospitalization for the entire cohort were USD 731,914 per patient. Charges per patient pertaining to hospitalizations in which ECMO was used in transplant patients were the highest: USD 1,448,931 and USD 1,574,378 $(P=.99)$ for $H T$ and $L T$, respectively. Charges were lower for the other indications: PCS USD 798,909, CS USD 655,099, and SARF USD 824,852. Overall mortality for the entire cohort was $55 \%$. PCS and CS ( $53 \%$ vs $58 \%, P=.34)$ had similar survival, whereas SARF was $45 \%$, LT was $39 \%$ and HT $32 \%$. There were no differences in survival in these latter indications (SARF, LT and HT). The cumulative charges (proportion $\times$ hospital charges) reveal that PCS and CS (39\% and $37 \%)$

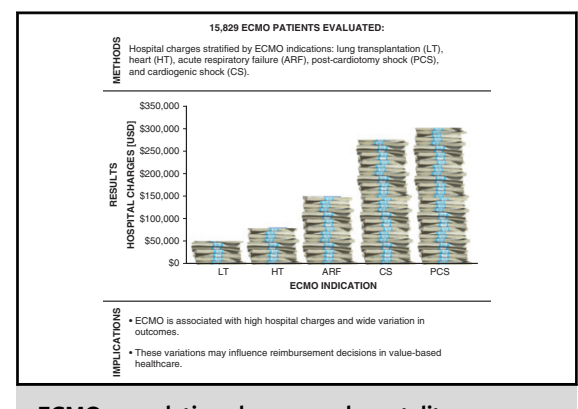

ECMO cumulative charges and mortality.

CENTRAL MESSAGE

ECMO hospitalizations for post-

cardiotomy shock and cardio-

genic shock are associated with

the greatest charges and the

lowest survival.

\section{PERSPECTIVE}

ECMO use in postcardiotomy and cardiogenic shock is a common occurrence. It is, however, associated with hospitalizations worth billions of dollars yet with comparatively low survival. value-based health care considerations may look unfavorably on the nonjudicious use of ECMO in the future.

See Commentaries on pages 71 and 73 .

\footnotetext{
From the ${ }^{\mathrm{a}}$ Department of Cardiovascular and Thoracic Surgery, Divisions of ${ }^{\mathrm{c}}$ Cardiac Anesthesia and ${ }^{\mathrm{f}}$ Cardiovascular Critical Care, WVU Heart and Vascular Institute, West Virginia University, Morgantown, WVa; ${ }^{b}$ Department of Cardiothoracic Surgery, Johns Hopkins University, Baltimore, Md; ${ }^{d}$ Department of Surgery, University of Colorado Health, Denver, Colo; and ${ }^{\mathrm{e} D e p a r t m e n t ~ o f ~ B i o s t a t i s t i c s, ~ G r a d u a t e ~}$ School of Public Health, University of Pittsburgh, Pittsburgh, Pa.

Read at the 99th Annual Meeting of The American Association for Thoracic Surgery, Toronto, Ontario, Canada, May 4-7, 2019.

Received for publication Feb 7, 2020; revisions received Feb 7, 2020; accepted for publication Feb 20, 2020; available ahead of print April 9, 2020.
}

Address for reprints: J. W. Awori Hayanga, MD, MPH, Department of Cardiovascular and Thoracic Surgery, West Virginia University, 1 Medical Center Dr, Morgantown, WV 26506 (E-mail: jeremiah.hayanga@wvumedicine.org). 2666-2736

Copyright $(C 2020$ by The Authors. Published by Elsevier Inc. on behalf of The American Association for Thoracic Surgery. This is an open access article under the CC BY-NC-ND license (http://creativecommons.org/licenses/by-nc-nd/4.0/). https://doi.org/10.1016/j.xjon.2020.02.003 


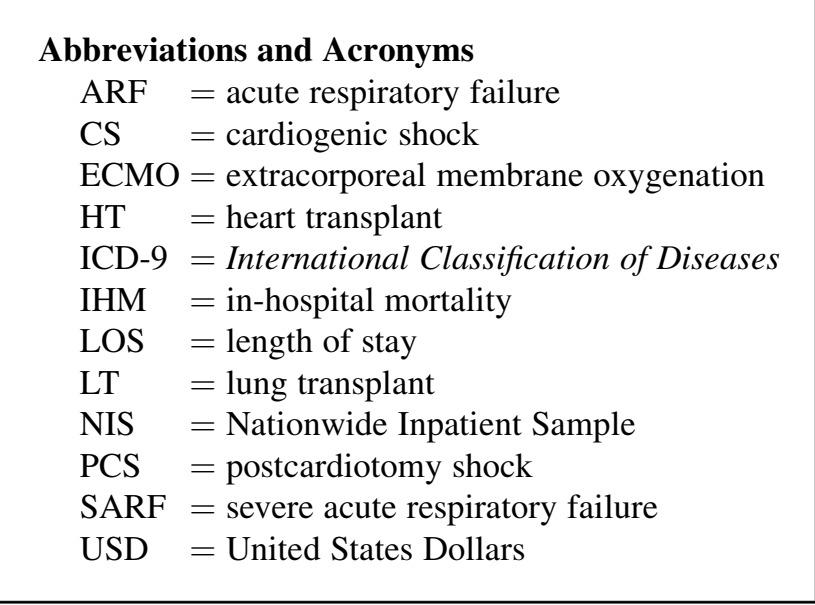

account for both the majority of charges as well as the greatest mortality. Conversely, SARF and transplantation accounted for the smaller proportion of charges and the lower mortality. Patients undergoing HT had the longest LOS (51.7 days) and duration on ECMO (15.9 days), followed by LT ( 35.4 and 8.8 days respectively), and patients with SARF (28.6 and 6.6 respectively). LOS and duration of ECMO for those with PCS were 18.7 days and 4.8 days, respectively. Those on ECMO for CS were hospitalized for 19.7 days and spent an average of 3.8 days on ECMO. Mortality decreased, whereas charges increased in the late era.

Conclusions: The use of ECMO is associated with high hospital charges and a wide variation in outcomes. Hospitalizations, in which ECMO is used to support patients with cardiogenic shock (PCS and CS), are individually associated with lower LOS and charges. Cumulatively, however, these account for greater charges and greater mortality. Although mortality may be decreasing, overall charges are increasing with time. These variations may influence reimbursement decisions in value-based healthcare. (JTCVS Open 2020;1:61-70)

Extracorporeal support is used increasingly to support patients with severe, acute cardiac and pulmonary failure. Indeed, it is rapidly becoming the option of first choice for support. Indications have been broadened to include severe influenza, bridging to heart (HT) and lung transplantation (LT), cardiogenic shock (CS) as well as, more traditionally, postcardiotomy shock (PCS). Extracorporeal support has increased by more than $400 \%$, and it is fast becoming a common feature in many high-volume centers in the United States. ${ }^{1-3}$ Similarly, use in the treatment of respiratory failure has also increased. In this vein, the CESAR (conventional ventilatory support vs extracorporeal membrane oxygenation for severe adult respiratory failure) trial elevated the popularity of extracorporeal membrane oxygenation (ECMO) support, providing a compelling rationale for the transfer of severely ill patients to ECMO centers for specialized care. ${ }^{4}$

The provision of extracorporeal support, however, is resource-intensive, and the associated costs are high. Various reports estimate these as ranging between US dollars (USD) 20,000 and 40,000 per day. ${ }^{5,6}$ Hospitalizations for PCS-ECMO are estimated at approximately USD 200,000 to 500,000 and where it is used as a bridge to LT, the median hospital charges are increased by as much as $50 \%{ }^{7}$ Despite these high costs, however, outcomes vary by indication. ${ }^{2}$ The best results have been demonstrated in the use of ECMO to treat adult respiratory distress syndrome, influenza, and as a bridge to transplantation., 4 Conversely, poor outcomes have been observed in CS, specifically in the context of cardiopulmonary resuscitation. Overall, advancements in technological design and clinical management have driven a dramatic improvement in ECMO outcomes over the past decade. As such, this past decade has been termed the "ECMO-2 era," distinguishing it from the poor outcomes before 2008. Surprisingly, however, despite the exorbitant costs of ECMO, there are few published analyses of charges or cost-effectiveness. The results of the CESAR trial justified ECMO use in the treatment of influenza A during the H1N1 pandemic but are not necessarily extrapolatable to any other kind of shock. ${ }^{4,9}$ In this study, we sought to use a national sample to describe the variation in charges for ECMO and mortality with different indications. With an evaluation of charges and outcomes, we aim to take a step closer toward a value-based appraisal of ECMO.

\section{METHODS}

The data analyzed were obtained from the Nationwide Inpatient Sample (NIS). The NIS is sponsored by the Agency for Healthcare Research and Quality and is part of the Healthcare Cost and Utilization Project. The data represent a $20 \%$ stratified sample of nonfederal, acute-care hospitals in all states in the United States, and it is the largest all-payer database of hospital inpatients admissions. ${ }^{10}$

\section{Study Population}

We included all hospital discharges between 2008 and 2016, for all adult patients (age 18 or older) supported on ECMO as defined by International Classification of Diseases (ICD), 9th Revision procedure code 39.65 and 10th Revision code 5A15233. We excluded recipients younger than the age of 18 years and those with missing data on age, sex, mortality, or hospital charges.

\section{Data Collection}

The primary outcome was hospital charges. We also evaluated inhospital mortality (IHM), length of hospitalization, and duration on ECMO stratified by clinical indication for descriptive purposes. Patient demographic variables analyzed included age, sex, race/ethnicity, and 
TABLE 1. ECMO indication ICD and CCS codes

\begin{tabular}{|c|c|c|c|}
\hline ECMO indication & ICD-CM-9 (procedure) & ICD-CM-10 & CCS diagnoses \\
\hline Post cardiotomy & 35.x, 36.x , 37.1, 37.3x, 441.x & $\begin{array}{l}\text { 02TN0ZZ, 02TN3ZZ, 02NN3ZZ, 025N0ZZ, 02CN0ZZ, } \\
\text { 02UM0JZ, 02U50JZ, 02QF0ZZ, 02QG0ZZ, } \\
\text { 02QH0ZZ, 02QJ0ZZ, 0210093, 02100A3, 02100J3, } \\
\text { 02100K3, 02100Z3, 021008W, 021009W, 02100AW, } \\
\text { 02100JW 02100KW, 021108W, 021109W, 02110AW, } \\
\text { 0211OJW, 02110KW"021208W, 02120AW, } \\
\text { 02120JW, 02120KW, 021308W, 021309W, 02130AW, } \\
\text { 02130JW, 02130KW, 0210088, 0210089, 021008C, } \\
\text { 0210098, 0210099, 021009C, 02100A8, 02100A9, } \\
\text { 02100AC, 02100J8, 02100J9, 02100JC, 02100K8, } \\
\text { 02100K9, 02100KC, 02100Z8, 02100Z9, 02100ZC, } \\
\text { 02100AF, 02100A3 }\end{array}$ & \\
\hline Cardiogenic shock & & $\begin{array}{l}\text { I502, I503, I5040, I5041, I5021, I5031, "I5020, I5039, } \\
\text { I5023, I5033, I5043, I97130, I97131, I219, "I39" I38, } \\
\text { I30, I31, I301, I300, I32" I40" I401, I514, I408, I409, } \\
\text { I4901, I97120, I469" I33" }\end{array}$ & $97,100,101,103,107,108$ \\
\hline Acute respiratory failure & & $\begin{array}{l}\text { J9620, J9600, J962, J9691, J9692, J9582, J9602, J9621, } \\
\text { J9622, J9690, J9600, R09 }\end{array}$ & $3,122,123,126,130,132$ \\
\hline Heart transplant & 37.51 & 02YA0Z0 & \\
\hline Lung transplant & $33.51,33.52$ & OBYK0Z0, OBYM0Z0, OBYLOZ0 & \\
\hline
\end{tabular}

ECMO, Extracorporeal membrane oxygenation; ICD-9 CM, International Classification of Diseases, Ninth revision, Clinical Modification; ICD-10 CM, International Classification of diseases, Tenth revision, Clinical Modification; CCS, clinical classifications software.

insurance status. We adjusted for disease burden using a modified version of the Charlson comorbidity index explicitly developed for use with administrative databases such as the NIS. ${ }^{11}$ Using specific ICD 9th Revision codes and Tenth Revision codes, we identified the 5 major indications for ECMO using a modified methodology from previous reports. ${ }^{1,3}$ These included PCS, CS, acute respiratory failure (ARF), pre- and post-HT, and pre- and post-LT. (Codes are available in Table 1.) This is a similar methodology used in other studies that have used the NIS, permitting the categorization of codes into mutually exclusive groups that, for example, allow CS to be evaluated in the absence of cardiac surgery, respiratory failure, or transplantation codes. ${ }^{3}$ Similarly, patients undergoing transplant were evaluated separately as either HT or LT recipients and excluded from those requiring support for PCS., ${ }^{2,3}$

\section{Statistical Analysis}

We used a data analytic approach accounting for the built-in weighting incorporated within NIS methodology. Descriptive statistics on the patient and hospital characteristics were obtained for the entire cohort. Because hospital charges were positively skewed, we used a generalized linear model with gamma distribution to calculate differences in total charges by ECMO indication. A pairwise comparison with Bonferroni correction was performed on predicted mean charges obtained from the model for each of the clinical indications. Variables included within the model were age, sex, race/ethnicity, Charlson comorbidity index, insurance status, hospital region, and year of procedure. All hospital charges were inflationadjusted using 2017 USD. We compared differences in charges between survivors and nonsurvivors. Similar models were fitted using length of

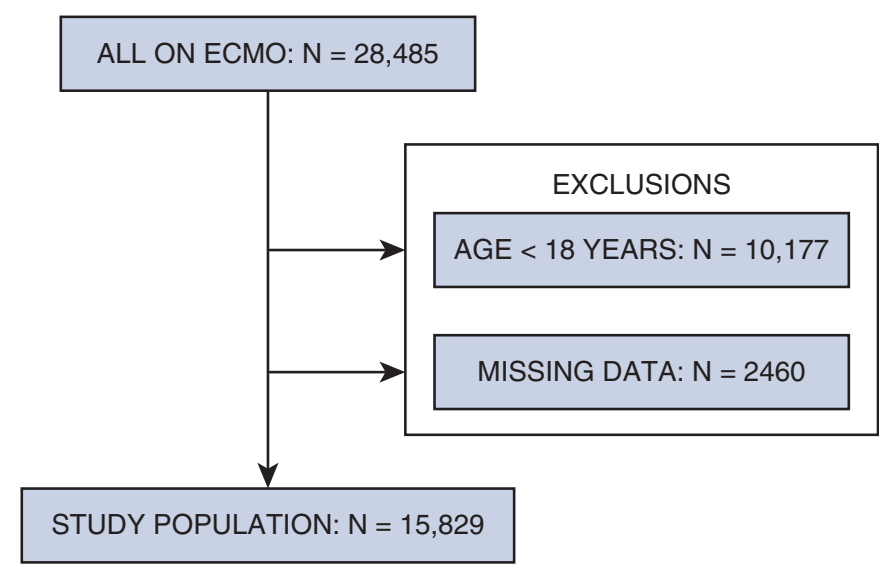

FIGURE 1. Chart illustrating patient inclusion criteria into study population. ECMO, Extracorporeal membrane oxygenation. 
TABLE 2. Patient- and hospital-level characteristics

\begin{tabular}{lc}
\hline \multicolumn{1}{c}{ Variable } & $\mathbf{N}=\mathbf{1 5 , 8 2 9}$ \\
\hline Mean age, $\mathrm{y}, \mathrm{SD}$ & $52.8(16.2)$ \\
Female sex, $\mathrm{n}(\%)$ & $5551(35)$ \\
\hline Race, $\mathrm{n}(\%)$ & \\
$\quad$ White & $8895(56)$ \\
Black & $2121(13)$ \\
Hispanic & $2516(16)$ \\
Other & $2297(15)$ \\
Indication for ECMO, n (\%) & \\
Postcardiotomy & $6148(39)$ \\
Cardiogenic shock & $5864(37)$ \\
Respiratory failure & $2350(15)$ \\
Pre/post-heart transplant & $611(3.9)$ \\
Pre/post-lung transplant & $855(5.4)$ \\
Insurance status, $\mathrm{n}(\%)$ & \\
Private & $6733(43)$ \\
Medicare & $5329(34)$ \\
Medicaid & $2636(17)$ \\
Other & 1130 \\
Hospital region & \\
Northeast & \\
Midwest & \\
South & \\
West & \\
Charlson Comorbidity index & \\
0 &
\end{tabular}

stay (LOS) and duration on ECMO as outcome variables. We performed a multivariable logistic regression to evaluate the association between clinical indication for ECMO and IHM, adjusting for the aforementioned variables. A similar pairwise comparison was performed on the predicted mortality rates by clinical indication for ECMO. To evaluate the impact of time on charges and mortality, we stratified the study period into 2 eras, early (2008-2012) and late (2013-2016). We fitted the aforementioned models individually for each era. A 2 -tailed $P<.05$ was considered statistically significant. All analyses were performed on STATA MP, Version 14 (StataCorp, College Station, Tex). This study was granted an exemption by West Virginia University of School of Medicine institutional review board.

\section{RESULTS}

Figure 1 shows the composition of the inclusion criteria used. A total of 15,829 patients were included in the analysis. Of the total, there were 5584 and 10,245 in the early and late eras, respectively. Female patients accounted for $35 \%$ of the population, $8895(56 \%)$ were white, and the mean age was 52.8 years. Postcardiotomy was the most common indication for ECMO (39\%), followed by CS $(37 \%)$. Acute respiratory failure accounted for $15 \%$, and HT and LT accounted for $3.9 \%$ and $5.4 \%$, respectively.
The mean LOS and duration on ECMO were 23.4 days and 5.3 days, respectively (Table 2). Table 3 depicts the distribution of these characteristics by ECMO indication.

\section{Hospital Charges}

The mean hospital charges in the entire cohort were USD 731,914. Tables 4 and 5 depict unadjusted and predicted mean hospital charges by clinical indication for ECMO, based on the adjusted model. In adjusted analysis, there were no statistically significant differences in total hospital charges between HT and LT recipients (USD 1,448,931 vs USD $1,574,378 ; P=.99$ ). These 2 indications had significantly greater total charges than any of the other indications. (PCS USD 798,909, CS USD 655,099, severe acute respiratory failure [SARF] USD 824,852). In a pairwise comparison, there were no differences between PCS and SARF. CS was associated with the lowest total individual hospital charges when compared with SARF, HT, and LT. There were no differences in charges between survivors and nonsurvivors for any indications except ECMO use for CS and PCS. In both these latter indications, survivors had greater hospital charges compared with nonsurvivors (Figure 2, A). In all indications, there was a statistically significant increase in average hospital charges from the early era (2008-2012) to the late-era (2012-2016) (Figure 2, B).

\section{Cumulative Charges}

The cumulative charges (proportion $\times$ hospital charges) show that PCS and CS (39\% and 37\%) account for both the most charges and the lowest survival. Conversely, SARF, and transplantation accounted for the smaller proportion of charges and higher survival (Figure 3).

\section{Mortality}

The in-hospital mortality for the entire cohort was 8727 $(55 \%)$. In the adjusted analysis, there was no difference in the IHM rate between PCS and CS $53 \%$ vs $58 \%$, $P=.34)$. Descriptively, the in-hospital mortality rate for patients with CS was greater than in patients with $\operatorname{ARF}(45 \%)$, pre/post HT (39\%), and pre/post LT (32\%). There were no differences in in-hospital mortality between patients with ARF compared with HT and LT recipients (Table 6). For all indications, however, there was a decrease in the risk of IHM in the late-era (Table 7).

\section{Length of Stay}

Heart transplant recipients had the most extended mean total hospital LOS (51.7 days) and duration on ECMO (15.9 days) compared with the other clinical indications for ECMO. LT recipients had the next most prolonged LOS (35.4 vs 8.8), followed by patients with SARF (28.6 vs 6.6). Mean hospital LOS and duration on ECMO for PCS patients were 18.7 days and 4.8 days, respectively. 
TABLE 3. Population characteristics by ECMO indication

\begin{tabular}{|c|c|c|c|c|c|}
\hline Variable & PCS & CS & SAR $(n=2350)$ & HTX & LUNGTX $(n=855)$ \\
\hline Mean age, y (SD) & $57.5(14.9)$ & $50.8(16.2)$ & $45.5(17.0)$ & $52.5(14.1)$ & $52.0(14.4)$ \\
\hline Female sex, n $(\%)$ & $1868(30)$ & $2117(36)$ & $1052(45)$ & $173(28)$ & $341(40)$ \\
\hline \multicolumn{6}{|l|}{ Race, n (\%) } \\
\hline White & $3555(58)$ & $3065(52)$ & $1363(57.9)$ & $344(56.3)$ & $568(66.4)$ \\
\hline Black & $674(11)$ & $887(15)$ & $341(14.9)$ & 144 (23.6) & $74(8.7)$ \\
\hline Hispanic & $1025(17)$ & 969 (17) & $357(15)$ & $64(10.5)$ & $101(11.8)$ \\
\hline Other & 894 (15) & 943 (16) & 289 (11.9) & $59(9.6)$ & $112(13.1)$ \\
\hline \multicolumn{6}{|l|}{ Insurance status, $\mathrm{n}(\%)$} \\
\hline Private & $2485(40)$ & $2565(44)$ & 954 (40.6) & $279(45.7)$ & $450(52.6)$ \\
\hline Medicare & $2468(39.9)$ & $1666(28)$ & $641(27.3)$ & $240(39.3)$ & $313(36.6)$ \\
\hline Medicaid & $831(14)$ & $1122(19)$ & $518(22)$ & $83(13.6)$ & $82(9.6)$ \\
\hline Other & $363(5.8)$ & $511(8.7)$ & $237(10.1)$ & $9(1.4)$ & $10(1.2)$ \\
\hline \multicolumn{6}{|l|}{ Hospital region } \\
\hline Northeast & $1764(29)$ & $1684(29)$ & $690(29.4)$ & $186(31)$ & $305(35.7)$ \\
\hline Midwest & $1556(25)$ & $1313(22)$ & 445 (18.9) & 105 (17) & $181(2.1)$ \\
\hline South & $1828(30)$ & $2007(34)$ & $861(36.6)$ & $215(35)$. & $250(29.2)$ \\
\hline West & 999 (16) & $860(15)$ & $355(15.1)$ & 104 (17.) & $120(14.0)$ \\
\hline \multicolumn{6}{|l|}{ Charlson Comorbidity index } \\
\hline 0 & $452(7.4)$ & $820(14)$ & $823(35)$ & $14(2.3)$ & $332(24.8)$ \\
\hline 1 & $1595(26)$ & $1414(24)$ & $582(24.8)$ & $135(22.1)$ & $323(37.8)$ \\
\hline$>1$ & $4101(67)$ & $3630(62)$ & $945(40.2)$ & $462(75.6)$ & $200(23.4)$ \\
\hline Mean length of stay, d (SE) & $19.5(22.7)$ & $19.7(22.6)$ & $28.9(28.3)$ & $51.4(56.8)$ & $41.3(40)$ \\
\hline $\begin{array}{l}\text { Mean length on ECMO, } \\
\text { d (SE) }\end{array}$ & $4.8(7.5)$ & $3.8(9.2)$ & $6.6(12.4)$ & $16.0(32.6)$ & $8.8(13.7)$ \\
\hline
\end{tabular}

PCS, Postcardiotomy shock; $C S$, cardiogenic shock; $S A R F$, severe acute respiratory failure; $H T X$, heart transplantation; $L U N G T X$, lung transplantation; SD, standard deviation; $S E$, standard error; $E C M O$, extracorporeal membrane oxygenation.

On average, patients with CS were hospitalized for 19.7 days and spent an average of 3.8 days on ECMO.

\section{DISCUSSION}

Several published reports have attempted to quantify trends in ECMO use over the past decade. It has been established that ECMO admissions increased by $369 \%$ between 2008 and 2014 . $^{2}$ When stratified by indication, the most substantial increase occurred in patients with respiratory failure. $^{2}$ Our results reflect a similar increase in ECMO use; however, this was predominantly for treating PCS and CS. Nevertheless, mortality associated with ECMO use has decreased, as our results have also shown. This has been primarily attributed independently to the decrease in mortality in the postcardiotomy cohort in whom inhospital age-adjusted mortality has reportedly dropped by $20 \%$, from $62 \%$ to $42 \%$. This has mainly been attributed to improvements in overall postcardiac surgery care and survival. $^{2}$

The majority of patients who receive ECMO are treated in large urban teaching hospitals. ${ }^{2,6}$ The trend is driven by the implicit assumption that high-volume centers are the de facto centers of excellence, a notion predicated on the volume-outcome relationship that has been observed and reported for complex surgical interventions and that tends to favor outcomes in these settings. ${ }^{12}$ The

TABLE 4. Unadjusted and adjusted hospital charges by indication for ECMO

\begin{tabular}{lcr}
\hline Indication for ECMO & Unadjusted charges $(\mathbf{9 5} \%$ CI) & Adjusted charges* (95\% CI) \\
\hline Postcardiotomy & $658,519(610,149.2-706,889)$ & $798,909(715,196-882,621)$ \\
Cardiogenic shock & $642,719(582,532.9-702,905.8)$ & $655,099(591,476-718,721)$ \\
Respiratory failure & $832,786(716,161.8-949,410.9)$ & $824,852(725,280-924,423.80)$ \\
Heart transplant & $1,362,123(1,175,213-1,549,033)$ & $1,448,931(1,252,694-1,645,167)$ \\
Lung transplant & $1,219,430(933,913.2-1,504,947)$ & $1,574,378(1,328,121-1,820,635)$ \\
\hline
\end{tabular}

ECMO, Extracorporeal membrane oxygenation; $C I$, confidence interval. *Adjusted for age, sex, race, comorbidities, hospital region, insurance status. 
TABLE 5. Pairwise comparison of adjusted hospital charge by ECMO indication

\begin{tabular}{|c|c|c|c|c|c|c|}
\hline Indication for ECMO & $\begin{array}{c}\text { Hospital } \\
\text { charge* (USD) }\end{array}$ & $\begin{array}{c}\text { Post } \\
\text { cardiotomy }\end{array}$ & $\begin{array}{c}\text { Cardiogenic } \\
\text { shock }\end{array}$ & $\begin{array}{c}\text { Acute respiratory } \\
\text { failure }\end{array}$ & $\begin{array}{c}\text { Heart } \\
\text { transplant }\end{array}$ & $\begin{array}{c}\text { Lung } \\
\text { transplant }\end{array}$ \\
\hline Post cardiotomy & 798,909 & & $<0.01$ & 0.99 & $<0.001$ & $<0.001$ \\
\hline Cardiogenic shock & 655,099 & & & $<0.001$ & $<0.001$ & $<0.001$ \\
\hline Acute respiratory failure & 824,852 & & & & $<0.001$ & $<0.001$ \\
\hline Heart Transplant & $1,448,931$ & & & & & 0.99 \\
\hline Lung transplant & $1,574,378$ & & & & & \\
\hline
\end{tabular}

ECMO, Extracorporeal membrane oxygenation; USD, US dollars. *Adjusted for age, sex, race, comorbidities, hospital region, insurance status.

volume-outcome relationship, however, is conspicuously different in the context of ECMO. ${ }^{13-15}$ Greater mortality has been observed in tandem with greater volume., ${ }^{3,13}$ Indeed, several theories have been proffered to explain this phenomenon and include, first, an acknowledgment that these centers tend to manage the highest-acuity patients consistent with the accepted, oft expected ethos of specialized centers. Second, the existence of programmatic "hub-and-spoke" models that effectively direct locoregional referrals to a main quaternary center from a peripheral base of community hospitals, often lacking the infrastructure to support patients on ECMO. ${ }^{2}$ The

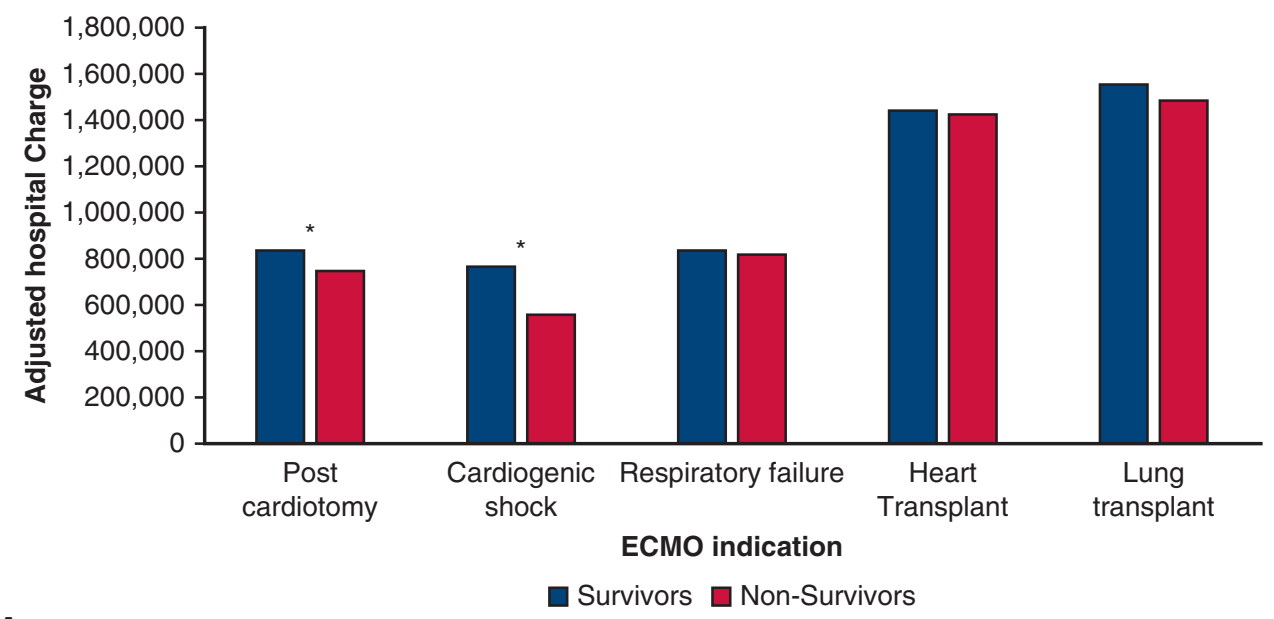

A

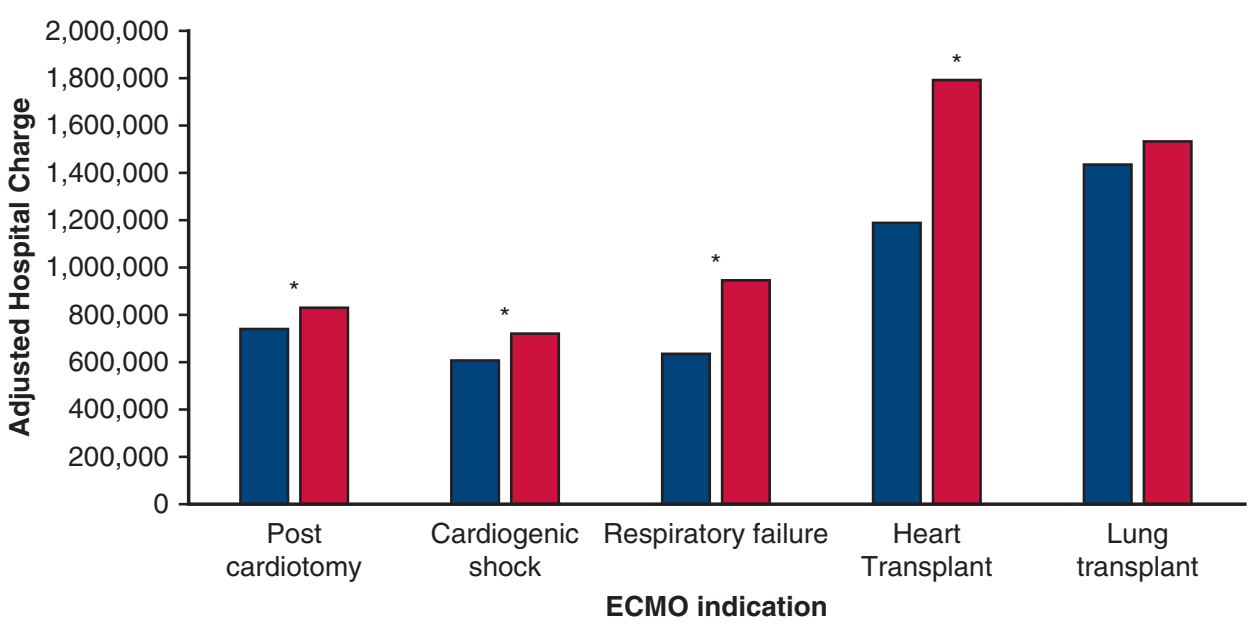

B

2008-2012 口2013-2016

FIGURE 2. A, Adjusted hospital charges for survivors and nonsurvivors by indication for ECMO indication. B, Adjusted hospital charges in the 2 eras, 2008-2012 and 2013-2016, by indication for ECMO. ECMO, Extracorporeal membrane oxygenation. 


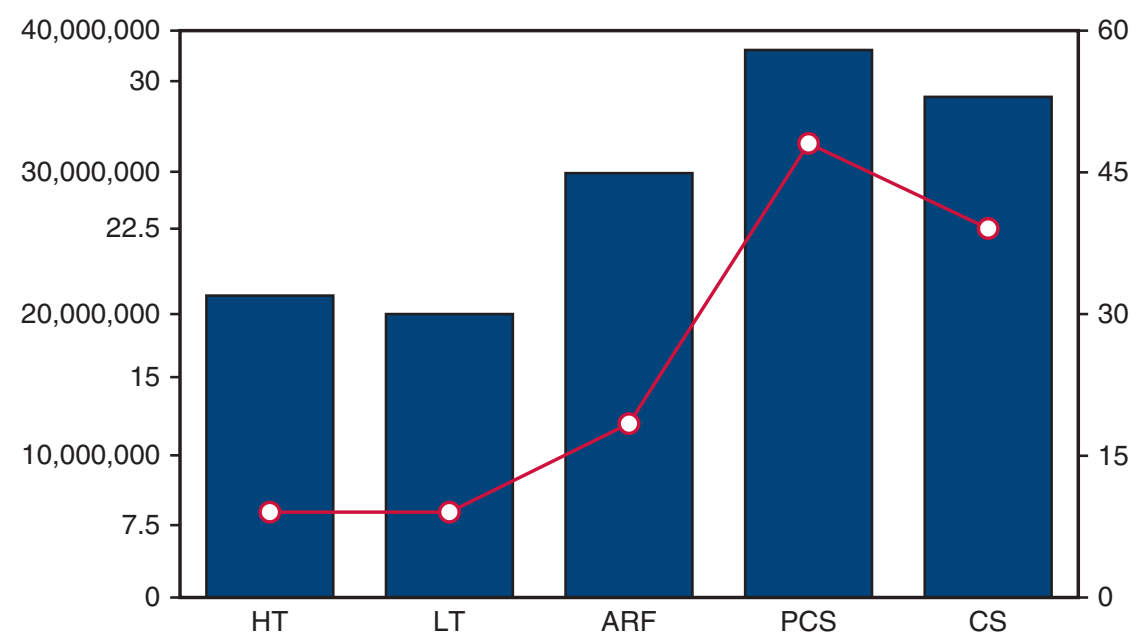

FIGURE 3. Cumulative charges and mortality per ECMO indication. $H T$, Heart transplant; $L T$, lung transplant; $A R F$, acute respiratory failure; $P C S$, postcardiotomy shock; $C S$, cardiogenic shock.

transfer to a higher level of care often occurs with little resistance from the receiving hospital, which must then assume an unpredictable burden of morbidity and mortality. Bailey and colleagues ${ }^{13}$ estimated mortality rates of $59 \%$ and $54 \%$ for transferred versus index patients, respectively. Third, quaternary referral centers replete with robust multidisciplinary infrastructure, and personnel may be more liberal with the use of ECMO. ${ }^{13}$

There is a notion, however, that the use of ECMO has outstripped existing evidence, and there is a growing demand for objective quantification and improvement of outcomes. Technological design and clinical expertise will promote the use of criteria to guide patient selection better and explicitly demarcate contraindications. In this way, enhance decision-making at the bedside. To this end, there has been an evolution in practice with a growing interest in left ventricular decompression to decrease left ventricular afterload and mitigate the distension that accompanies the pressurization of the arterial system in venoarterial ECMO. ${ }^{16,17}$ This is viewed as a means of optimizing cardiac function and may be achieved through several different techniques that include atrial septostomy, placing a vent through the left ventricle and most commonly, through the use of an Impella device (Abiomed, Danvers, Mass) or intra-aortic balloon pump. ${ }^{16-21}$

Mortality is greatest in patients with CS and lowest in patients at post-transplantation. The opposite is true, however, for LOS. Comparison of charges, however, yields diametrically opposite results depending on whether the consideration is individual or cumulative hospitalizations. Individual hospitalizations are lowest in CS but greatest in transplantation. For cumulative charges, however, the opposite is true, and these are driven, not by the seemingly high cost of transplantation, but by the comparatively greater volume of individual PCS-ECMO cases compared with the fairly small, and relatively stable, number of transplantations requiring ECMO. The mean total charges per hospitalization range from USD 97,000 to 600,000 . $^{6}$ The median duration of ECMO has been estimated at 9 days. $^{6}$ The average LOS is 18 days., ${ }^{3,22}$ The use of ECMO for cardiac conditions was associated with a mean of USD 530,000. ${ }^{6}$ These charges have increased in the later years, with the majority of the costs attributed to personnel, often perfusionists or ECMO specialists at the bedside. Medication and procedures surprisingly represent less than $10 \%$ of charges. $^{23,24}$ This underscores the value in training a "homegrown" institution-specific cadre of nursing staff and respiration therapists capable of performing the bedside monitoring to mitigate the daily costs, reportedly ranging from USD 18,000 and USD 40,000. ${ }^{6,25}$ Indeed, in our own experience, a perfusion-led program can result in triple the costs.

The majority of published reports on the high cost of ECMO typically report these in the context of individual cases and hospitalizations. In these discussions, transplantation is highlighted as a costly indication for ECMO. Indeed, the use of ECMO as a bridge to LT raises charges by $50 \%$. That notwithstanding, the total number of cases in which ECMO was used in this manner between 2005 and 2017 was only 600 . In the same vein, the total number of heart transplants performed in any given year rarely exceeds 3500. Thus, transplantation charges seem much higher in comparison, whereas, in reality, the number of patients undergoing transplantation is much smaller. PCS accounts for $57 \%$ of all ECMO cases. ${ }^{2}$ The corresponding comparative cumulative charges for hospitalization are also much lower. A focus on cumulative charges per indication and provides a unique global portrait of the financial footprint by ECMO on the health system as a whole. 
TABLE 6. Mortality pairwise comparisons of in-hospital mortality by ECMO indication

\begin{tabular}{|c|c|c|c|c|c|c|}
\hline & Mortality* & Post cardiotomy & Cardiogenic shock & Acute respiratory failure & Heart transplant & Lung transplant \\
\hline Postcardiotomy & $0.53(0.49-0.57)$ & & 0.34 & 0.06 & 0.03 & $<0.01$ \\
\hline Cardiogenic shock & $0.58(0.54-0.61)$ & & & $<0.01$ & $<0.01$ & $<0.01$ \\
\hline Acute respiratory failure & $0.45(0.40-0.49)$ & & & & 0.99 & 0.19 \\
\hline Heart transplant & $0.39(0.31-0.48)$ & & & & & 0.99 \\
\hline Lung transplant & $0.32(0.23-0.41)$ & & & & & \\
\hline
\end{tabular}

Adjusted for age, sex, race, comorbidities, hospital region, insurance status. $* P<.05$.

The staggering scope of charges is likely to spark a debate about the establishment of criteria for eligibility. This, in the case of PCS and CS, is likely to favor patients with the most optimal outcomes who typically have been younger and with fewer comorbidities without the burden of advanced age, ischemic cardiomyopathy, or right ventricular failure, each of which impairs survival. Indeed, recovery is typically apparent within 4 days of support, beyond which mortality is greater. ${ }^{26-28}$ As the collective experience expands further, a variety of contraindications is likely to emerge. Aortic dissection, for example, has a particularly poor prognosis and is slowly emerging as a contraindication. Anecdotally, patients with infective endocarditis also have poor outcomes with the use of ECMO and represent a growing contraindication for extracorporeal support. The duration of support also proffers prognostic value, and typically, patients who do not respond clinically within 4 days have poor survival. The timely identification of these patients may allow early determination of futility. It may be used to define a set of contraindications to extracorporeal support, particularly in the context of CS and extracorporeal cardiopulmonary resuscitation. ${ }^{29}$

Respiratory failure and transplantation are associated with the lowest mortality, whereas patients receiving ECMO support for CS have the greatest mortality. A vast amount of resources is, thus, paradoxically, spent on patients with the lowest chances of survival. Previous cost considerations have centered on the price of individual hospitalization, and, as such, transplantation dominates the single hospitalization cost category at approximately USD 1 million. Transplant hospitalizations, however, are, in turn, characterized by prolonged LOS, whereas those associated with CS are significantly shorter. ${ }^{3,6,30}$ These lower costs and the short LOS, however, are each counterbalanced by the sheer magnitude of the volume of ECMO used for CS and represent a considerably larger denominator. ${ }^{6,30}$ There is a pressing impetus to contain costs and prove the value of resource-intensive technologies currently deployed in contemporary health care and injudicious use of ECMO in the face of dire survival probability may come under greater scrutiny and disapproval. Whereas this may not be the first report of the magnitude of charges attributable to cardiogenic indications for ECMO, this will be the first that addresses the quantity in cumulative terms. There is a growing trend toward value-based rather than volumebased models of care, and the federal government has already attempted to reconfigure ECMO reimbursement. Health economists, however, will likely continue to seek metrics to quantify and improve the quality of care in a bid to reduce healthcare costs and allow more thoughtful and stringent selection of candidates.

The study has several limitations. First, the use of total charges does not equate to cost and there is a complicated, nonlinear relationship between reimbursement, charges, and cost. Second, the use of ICD codes does not allow for any distinction between venoarterial and venovenousECMO support. Third, the use of administrative data is fraught with bias and missing data as well as a likely host of other unmeasured confounding factors. Fourth, because the data pertain only to centers in the United States, the results may not necessarily be generalizable, particularly as costs in the United States are often in excess of this in non-US settings. Fifth, we did not calculate incremental costs that would have served to differentiate costs between those patients who received support versus those who did not. Sixth, the charges here pertain to the entire hospitalization and are not necessarily ECMO-specific. Furthermore,

TABLE 7. Comparison of risk-adjusted mortality stratified by era (2008-2012 and 2013-2016) per ECMO indication

\begin{tabular}{lcccc}
\hline Indication for ECMO & $\mathbf{2 0 0 8 - 2 0 1 2}$ & $\mathbf{2 0 0 9 - 2 0 1 6}$ & $\boldsymbol{P}$ value \\
\hline Postcardiotomy & $0.59(0.51-0.68)$ & $0.49(0.44-0.54)$ & $<.001$ \\
Cardiogenic shock & $0.65(0.57-0.73)$ & $0.52(0.49-0.56)$ & $<.001$ \\
Respiratory failure & $0.50(0.40-0.59)$ & $0.40(0.35-0.45)$ & .002 \\
Heart transplant & $0.48(0.34-0.63)$ & $0.34(0.23-0.46)$ & .04 \\
Lung transplant & $.0 .44(0.2-0.60)$ & $0.14(0.02-0.65)$ & .002 \\
\hline
\end{tabular}

ECMO, Extracorporeal membrane oxygenation. 
the limitations related specifically to the use of NIS data are myriad and include the inability to evaluate center-specific volume outcomes, discharges outside the index center, long-term outcomes, differences between perfusion-led and specialist-led models, or identify patients bridged to destination therapy. To this end, there are no data regarding concomitant devices or techniques such as left ventricular venting or the use of Impella intra-aortic- balloon pump, etc. Finally, the absence of granular detail precludes the ability to perform a more detailed risk-adjustment, which would, in turn, proffer an even more accurate analysis.

In summary, this is the first study to report ECMO survival in the context of cumulative charges stratified by indication in the contemporary era, highlighting the billion-dollar impact it bears on the health care system. Like previous studies, it highlights the disproportionate burden that PCS exerts on mortality at an individual level and acknowledges that this is increasing with time. ${ }^{31}$ As such, we also draw attention to the excess financial burden borne by the sheer volume of cases and proffer a lens through which interventions and policy may be viewed and challenged to refine the selection process and indications for ECMO, seeking to perpetuate the quest for improved quality and accountability so as to satisfy the needs of a system that is leaning ever closer to valuebased model of health care delivery.

\section{Webcast}

You can watch a Webcast of this AATS meeting presentation by going to: https://aats.blob.core.windows.net/ media/19\%20AM/Sunday_May5/206AC/206AC/S42\% 20-\%20Rapide \%20Fire \%20Abstracts \%20II/S42_5_ webcast_080821756.mp4.

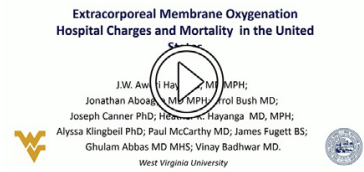

\section{Conflict of Interest Statement}

The authors reported no conflicts of interest.

The Journal policy requires editors and reviewers to disclose conflicts of interest and to decline handling or reviewing manuscripts for which they may have a conflict of interest. The editors and reviewers of this article have no conflicts of interest.

\section{References}

1. McCarthy FH, McDermott KM, Kini V, Gutsche JT, Wald JW, Xie D, et al. Trends in US extracorporeal membrane oxygenation use and outcomes: 2002-2012. Semin Thorac Cardiovasc Surg. 2015;27:81-8.
2. Sanaiha Y, Bailey K, Downey P, Seo YJ, Aguayo E, Dobaria V, et al. Trends in mortality and resource utilization for extracorporeal membrane oxygenation in the United States: 2008-2014. Surgery. 2019;165:381-8.

3. Maxwell BG, Powers AJ, Sheikh AY, Lee PH, Lobato RL, Wong JK. Resource use trends in extracorporeal membrane oxygenation in adults: an analysis of the nationwide inpatient sample 1998-2009. J Thorac Cardiovasc Surg. 2014; 148:416-21

4. Peek GJ, Mugford M, Tiruvoipati R, Wilson A, Allen E, Thalanany MM, et al. Efficacy and economic assessment of conventional ventilatory support versus extracorporeal membrane oxygenation for severe adult respiratory failure (CESAR): a multicentre randomised controlled trial. Lancet. 2009;374: 1351-63.

5. Mahle WT, Forbess JM, Kirshbom PM, Cuadrado AR, Simsic JM, Kanter KR. Cost-utility analysis of salvage cardiac extracorporeal membrane oxygenation in children. J Thorac Cardiovasc Surg. 2005;129:1084-90.

6. Harvey MJ, Gaies MG, Prosser LA. US and international in-hospital costs of extracorporeal membrane oxygenation: a systematic review. Appl Health Econ Health Policy. 2015;13:341-57.

7. Hayanga JA, Shigemura N, Aboagye JK, Ensor C, Dew MA, Hayanga HK, et al. ECMO support in lung transplantation: a contemporary analysis of hospital charges in the United States. Ann Thorac Surg. 2017;104:1033-9.

8. Hayanga AJ, Aboagye J, Esper S, Shigemura N, Bermudez CA, D’Cunha J, et al. Extracorporeal membrane oxygenation as a bridge to lung transplantation in the United States: an evolving strategy in the management of rapidly advancing pulmonary disease. J Thorac Cardiovasc Surg. 2015;149:291-6.

9. Peek GJ, Clemens F, Elbourne D, Firmin R, Hardy P, Hibbert C, et al. CESAR: conventional ventilatory support vs extracorporeal membrane oxygenation for severe adult respiratory failure. BMC Health Serv Res. 2006;6:163.

10. Healthcare Cost and Utilization Project (HCUP). Overview of the National (Nationwide) Inpatient Sample (NIS). Rockville, MD: Agency for Healthcare Research and Quality; 2012.

11. Elixhauser A, Steiner C, Harris DR, Coffey RM. Comorbidity measures for use with administrative data. Med Care. 1998;36:8-27.

12. Reames BN, Ghaferi AA, Birkmeyer JD, Dimick JB. Hospital volume and operative mortality in the modern era. Ann Surg. 2014;260:244.

13. Bailey KL, Downey P, Sanaiha Y, Aguayo E, Seo YJ, Shemin RJ, et al. National trends in volume-outcome relationships for extracorporeal membrane oxygenation. J Surg Res. 2018;231:421-7.

14. Ko WJ, Lin CY, Chen RJ, Wang SS, Lin FY, Chen YS. Extracorporeal membrane oxygenation support for adult postcardiotomy cardiogenic shock. Ann Thorac Surg. 2002;73:538-45.

15. McCarthy FH, McDermott KM, Spragan D, Hoedt A, Kini V, Atluri P, et al. Unconventional volume-outcome associations in adult extracorporeal membrane oxygenation in the United States. Ann Thorac Surg. 2016;102:489-95.

16. Tepper S, Masood MF, Garcia MB, Pisani M, Ewald GA, Lasala JM, et al. Lef ventricular unloading by Impella device versus surgical vent during extracorporeal life support. Ann Thorac Surg. 2017;104:861-7.

17. Vallabhajosyula S, O'Horo JC, Antharam P, Ananthaneni S, Vallabhajosyula S, Stulak JM, et al. Impella on top of ECMO treatment in cardiogenic shock results in effective left ventricular unloading. Presented at: EuroIntervention; 2015.

18. Vallabhajosyula S, O'Horo JC, Antharam P, Ananthaneni S, Vallabhajosyula S, Stulak JM, et al. Concomitant intra-aortic balloon pump use in cardiogenic shock requiring veno-arterial extracorporeal membrane oxygenation: a systematic review and meta-analysis. Circ Cardiovasc Interv. 2018;11:e006930.

19. Pappalardo F, Schulte C, Pieri M, Schrage B, Contri R, Soeffker G, et al. Concomitant implantation of Impella ${ }^{\circledR}$ on top of veno-arterial extracorporeal membrane oxygenation may improve survival of patients with cardiogenic shock. Eur J Heart Fail. 2017;19:404-12.

20. Stulak JM, Dearani JA, Burkhart HM, Barnes RD, Scott PD, Schears GJ. ECMO cannulation controversies and complications. Semin Cardiothorac Vasc Anesth. 2009; 13:176-82.

21. Russo JJ, Aleksova N, Pitcher I, Couture E, Parlow S, Faraz M, et al. Left ventricular unloading during extracorporeal membrane oxygenation in patients with cardiogenic shock. J Am Coll Cardiol. 2019;73:654-62.

22. Snell GI, Rabinov M, Griffiths A, Williams T, Ugoni A, Salamonsson R, et al. Pulmonary allograft ischemic time: an important predictor of survival after lung transplantation. J Heart Lung Transplant. 1996;15:160-8.

23. Mishra V, Svennevig JL, Bugge JF, Andresen S, Mathisen A, Karlsen H, et al Cost of extracorporeal membrane oxygenation: evidence from the Rikshospitalet University Hospital, Oslo, Norway. Eur J Cardiothorac Surg. 2010;37: $339-42$. 
24. Tseng YH, Wu MY, Tsai FC, Chen HJ, Lin PJ. Costs associated with extracorporeal life support used in adults: a single-center study. Acta Cardiol Sin. 2011;27: 221-8.

25. Bott R. Applied methods of cost-effectiveness analysis in health care. Igarss. 2014;2014:1-5.

26. Fux T, Holm M, Corbascio M, Lund LH, van der Linden J Venoarterial extracorporeal membrane oxygenation for postcardiotomy shock: risk factors for mortality. J Thorac Cardiovasc Surg. 2018;156: 1894-902.

27. Chen SW, Tsai FC, Lin YS, Chang CH, Chen DY, Chou AH, et al. Long-term outcomes of extracorporeal membrane oxygenation support for postcardiotomy shock. J Thorac Cardiovasc Surg. 2017;154:469-77.
28. Grunau B, MacRedmond R, Gill J. A promising therapy in jeopardy. Circulation. 2019:139:425-7.

29. Distelmaier K, Wiedemann D, Binder C, Haberl T, Zimpfer D, Heinz G, et al. Duration of extracorporeal membrane oxygenation support and survival in cardiovascular surgery patients. J Thorac Cardiovasc Surg. 2018;155:2471-6.

30. Vallabhajosyula S, Arora S, Sakhuja A, Lahewala S, Kumar V, Shantha GP, et al. Trends, predictors, and outcomes of temporary mechanical circulatory support for postcardiac surgery cardiogenic shock. Am J Cardiol. 2019;123:489-97.

31. Whitman GJ. Extracorporeal membrane oxygenation for the treatment of postcardiotomy shock. J Thorac Cardiovasc Surg. 2017;153:95-101.

Key Words: ECMO, mortality, outcomes, charges 